Charul A. Munshi MB BS M. Saced Dhamee MB BS Shantilal K, Gandhi MB FFARCs

\title{
Postoperative unilateral facial oedema: a complication of acute flexion of the neck
}

A case report describing a complication following the use of the sitting position and an extreme flexed position of the neck is presented. The patient developed unilateral oedema of the face, tongue and soft tissues of the mouth. The trachea was reintubated and the oedema subsided without treatment. The cause of the oedema is believed to be obstruction of the venous drainage of the head and neck.

\section{Key words}

COMPLICATIONS: oedema, airway obstruction.

The sitting position is used frequently for craniotomies and cervical operations. Placing the head above the heart improves the venous drainage of the head and neck thus minimizing venous bleeding.

We report the case of a young boy who developed unilateral facial oedema in the postoperative period following craniotomy in the sitting position with extreme flexion of neck.

\section{Case report}

An eight-year-old $(29 \mathrm{~kg}$ ) male was admitted to the hospital with signs of an intracranial haemorrhage resulting from the rupture of an arterio-venous malformation (AVM) into the ventricular system.

From the Department of Anaesthesiology, The Medical College of Wisconsin, Milwaukee, Wisconsin.

Address correspondence to: M. Saeed Dhamee MB, Bs, Deparment of Anesthesiology, The Medical College of Wisconsin, 8700 West Wisconsin Avenue, Milwaukee, Wisconsin 53226 U.S.A.
He was scheduled for right occipito-parietal craniotomy for excision of the AVM and evacuation of the haematoma. His past history was unremarkable and the general physical examination was normal. He was awake and alert before the operation. Anaesthesia was induced with thiopentone and relaxation for intubation was produced by pancuronium. The trachea was intubated under direct vision with $5.5 \mathrm{~mm}$ tracheal tube, without any difficulty or trauma. Anaesthesia was maintained with oxygen, nitrous oxide, and halothane. Ventilation was controlled to keep the $\mathrm{PaCO}_{2}$ at $30 \mathrm{mmHg}$. The operation was done with the patient in the sitting position with the head turned towards the left, the neck flexed and with the chin touching the anterior chest wall. Excision of the AVM was completed in ten hours. It was noticed during the operation that the brain was firm and remained so in spite of removal of cerebrospinal fluid and hyperventilation. Intravenous Mannitol $30 \mathrm{~g}$ and furosemide $10 \mathrm{mg}$ did not improve the condition of the brain.

The trachea was extubated soon after the patient's arrival in the recovery room. At that time he was awake, alert, moving all extremities and was noticed to have a small, firm submandibular swelling on the left side. Twenty minutes after extubation the patient was seen to be in respiratory distress and had developed inspiratory stridor. He was given positive pressure ventilation with oxygen and the trachea was reintubated under direct vision with $5.0 \mathrm{~mm}$ tracheal tube. Forty per cent oxygen was administrated by " $T$ " piece. There was no respiratory distress following intubation. At this stage the submandibular swelling had increased in size and 
had a red circular area on the anterior neck in the region of the hyoid bone. Examination of the oral cavity revealed oedema of the floor of the mouth and tongue beyond the anterior one-third. Direct laryngoscopy revealed no oedema of the glottis, epiglottis or pharynx. The patient was nursed in the semi-sitting position. During the next twenty-four hours the swelling in the left neck increased and oedema around the left eye was now evident. On the second postoperative day the swelling of the neck and face persisted but there still was no oedema of the glottic or epiglottic region. The trachea was extubated at this stage and he was able to maintain the airway without difficulty. The swelling of the neck, eye, and tongue was cleared completely by the fifth postoperative day, with the patient nursed in a semirecumbent position. No drugs were administered.

\section{Discussion}

The sitting position with the neck flexed and head tumed to one side is employed commonly in neurosurgical procedures to provide better surgical exposure and improve venous and cerebrospinal fluid drainage.

The use of the sitting position during anaesthesia is associated with several complications. Hypotension due to venous pooling in dependent areas, ${ }^{1,2}$ fall in cardiac index with increase in systemic vascular resistance, ${ }^{3}$ displacement and/or kinking of the endotracheal tube, ${ }^{4}$ and a decrease in diffusion capacity due to decreased perfusion of the upper zones of lungs, ${ }^{5}$ are some of the common complications. This position, when used for the surgery of head or neck, is also associated with a high incidence of venous air embolism. ${ }^{3,6}$

Although oedema of the face is a common complication during use of the Trendelenberg position, it is uncommon in the sitting position. Oedema is produced by alterations in capillary hydrostatic forces or capillary permeability or interference with the venous or lymphatic drainage. Decreased colloid osmotic pressure and greatly increased intrathoracic pressures during bucking on an endotracheal tube were postulated as causes of facial oedema in a patient with chronic hepatic disease. ${ }^{7}$ Allergic reactions to a drug given systemically or applied locally may cause oedema due to increased capillary permeability. Facial oedema is a common

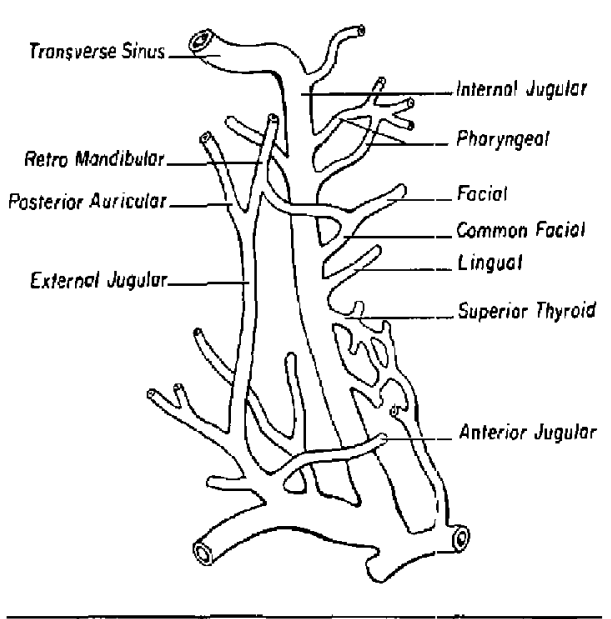

FIGURE I Venous drainage system of the head and neck showing tributaries of the internal jugular vein.

occurrence in an adverse reaction to an intravenous agent. ${ }^{8}$ Unilateral oedema excludes clrug reactions. No drugs or adhesive tape had been applied locally to the area of swelling. Tension pneumothorax with or without subcutancous emphysema by interfering with venous drainage, ${ }^{9}$ or obstruction from thrombosis of jugular veins may cause facial oedema. ${ }^{10}$ Acute and transient swelling of the salivary glands ("anesthetic mumps") is another rare cause of facial swelling. ${ }^{11,12}$

We believe that initially the facial oedema in our patient resulted from obstruction of the left internal jugular vein caused by the excessive flexion of the neck and rotation of the head to the left. The venous drainage of the area is illustrated in Figure 1 . The obstruction of venous return will also explain the inability to reduce brain size during the operation, in spite of the use of hyperventiliation, diuretics and removal of cerebrospinal fluid. Halothane is known to increase cerebrospinal fluid pressure. Halothane in 0.5 per cent concentration (as was used in this case) increases cercbral blood flow by about 10 per cent, ${ }^{13}$ but hyperventilation before introduction of halothane is usually sufficient to offitet that degree of increase in cerebral blood flow. ${ }^{14}$

Venous stasis predisposes to venous thrombosis. We suggest that this might have occurred in our 
patient, to account for the progression of the postoperative facial oedema. Venograms were not obtained to confirm the clinical diagnosis.

This case emphasizes again that great care must be taken in positioning the anaesthetized patient. Meticulous physical examination should be undertaken before and after the operation to detect signs of vaseular compression, such as engorgement of the neck veins. Swelling of the tongue and soft tissues of the floor of the mouth can compromise the patient's airway, necessitating intubation, as illustrated by this case report.

\section{References}

1 Campkin $T V$. Turner $I_{M}$. Anaesthesia for posterior fossa surgery. In: Neurosurgical Anaesthesia and Intensive Care, Londen: Butterworth, 1981.

2 Enderby GEH. Postural ischaemia and blood pressure. Lancet $1953 ; 1: 185-7$.

3 Albin MS, Jennata PJ, Maroon JC, Tung A, Miller $J E$. Anaesthesia in the sitting position. Proccedings, IV European Congress of Anaesthesiology, Amsterdam. Excerpta Medica - 1974, 775.

4 Newfield $P$. Anesthesia for posterior fossa procedures in anesthesia and neurosurgery. Ed. Cottrell JE, Turndorf H. 1 st edition, St. Louis, CV Mosby Co. $1980,168-82$.

5 Gurtner GH, Fowler WS. Interrelationship of factors affecting pulmonary diffusing capacity. J Appl Physiol 1971; 30: 619-24.

6 Lassen NA. Control of cercbral circulation in health and disease. Circ Res 1974; 34: 749-60.

7 Conacher $1 D$. Acute onset facial oedema - A com. plication of extubation, Anaesthesia 1981 ; 36: 45-7.

8 Clark RSJ, Dundee JW, Garret RT, McArdle $G K$, Sutton JA. Adverse reactions to intravenous anaesthetics - a review of 100 reports. Br J Anaesth 1975; 47: 575-85.

9 Dhamee MS, Gandhi SK. Pneumothorax under anaesthesia: Middle East J Anaesth 1980; 5: 535-8.

10 McAllister $R G$. Macroglossia - A positional complication. Anesthesiology 1974; 40: 199-200.

11 Reilley $D J$. Benign transient swelling of the parotid gland following general anesthesia - anesthetic mumps. Anesth Analg 1970; 49:560-3.

12 Matuski A, Wakayama S, Oyama 7 . Acute transient swelling of the salivary glands during and following endotracheal anaesthesia. Anaesthesist 1975; 24 : 125-6.
13 McDowall $D G$. The effects of clinical concentration of halothane on blood flow and oxygen uptake of the cerebral cortex. Br J Anaesth 1967; 39: 186-96.

14 Adams RW, Gronert GA, Sundt TM, Michenfelder $J D$. Halothane hypocapnia and cerebrospinal fluid pressure in neurosurgery. Anesthesiology 1972; 37: 510-7.

\section{Résumé}

On rapporte une complication de la position assise avec flexion extrême du cou. Le patient a développé un oedème de la face, de la langue et des tissus mous de la bouche. On réintuba le patient et l'oedème régressa spontanément. On attribue cat oedème à une obstruction au drainage veineux de la tête et du cou. 